\section{Division Size and Timing Influence Propagation of Four Species of Epimedium L.}

\author{
Jessica D. Lubell ${ }^{1}$ and Mark H. Brand ${ }^{2}$ \\ Department of Plant Science, U-4067, University of Connecticut, Storrs, \\ CT 06269-4067
}

Additional index words. herbaceous perennial, rhizome, propagule

\begin{abstract}
Epimedium is a genus of shade tolerant herbaceous perennials and groundcovers that are slow growing and command high prices. This research examined the influence of division size and timing on propagation success and growth of $E$. pinnatum ssp. colchicum Boiss., E. × rubrum Morren, E. × versicolor 'Sulphureum' Morren and E. × youngianum Fisch. To determine an appropriate division size for each species, small (single bud) and large (three bud) divisions were made in mid-June 2002 and 2003. For the timing study, uniform divisions (three to five buds for $E$. pinnatum $\mathrm{ssp}$. colchicum and $E . \times$ versicolor 'Sulphureum'; four to seven buds for $E$. $\times$ rubrum and $E$. $\times$ youngianum) were made in March, late June and late August, when plants were dormant, had just completed foliage expansion, or were summer dormant. Half of the plants were destructively harvested in the fall and half were overwintered and forced in the greenhouse in early spring. By the end of the growing season, plants grown from large divisions were larger than those grown from small divisions and had produced more buds, however, plants from small divisions produced more buds per initial bud than plants from large divisions, demonstrating a faster increase in growing points. For each species, March divisions produced more vegetative growth, buds, buds per initial bud and potential propagules than June and August divisions, by the end of the growing season. However, by the following spring, both March and June divisions had produced plants of similar size and appearance, while plants grown from August divisions were smaller and of lower quality.
\end{abstract}

The development and use of new or underutilized plants is important to nursery producers, landscape architects and gardeners alike. Currently, there is building interest in the genus Epimedium, because of its garden versatility, diverse ornamental attributes and potential economic value. Epimediums are shade-tolerant herbaceous perennials and groundcovers, which thrive under trees and shrubs where few other plants will perform well. If properly sited, they require minimal care once established in the garden, and persist for many years. Their evergreen, semi-evergreen or deciduous leaves often emerge red in spring, turn green for the summer, and then color up again in the fall. Elegant, bell-shaped and often spurred flowers occur in various colors in spring. Epimediums are commonly propagated by rhizome division to preserve cultivar identity and because of low seed viability (Nau, 1996; Probst, 1998).

The increased interest in epimediums has made production of these plants in commercial nurseries economically important, but knowledge regarding optimal cultural requirements, nursery production methods and propagation is limited. Unlike many other herbaceous perennials, epimediums are slow growing. As a result, few propagules (divisions) may be taken from individual stock plants. In addition, it may

Received for publication 12 Nov. 2004. Accepted for publication 29 Jan. 2005. This paper is from a thesis submitted by the senior author in partial fulfillment of the requirements for the MS degree.

${ }^{1}$ Graduate research assistant.

${ }^{2}$ Professor. To whom reprint requests should be addressed; e-mail mark.brand@uconn.edu. take up to two growing seasons for nurseries to produce a salable plant from these divisions. This slow generation time consumes production resources, resulting in a higher wholesale cost per plant, which must be passed along to consumers. Common epimedium varieties used in this study typically cost $40 \%$ more than other shade perennials (Sunny Border Incorporated, 2003; The Plant Group Incorporated, 2003). Other less common Epimedium species and cultivars retail for $\$ 25$ to $\$ 100$ for 2 -inch pot liners and are currently unavailable in larger sizes (Probst, 2004).

Our research focused on optimizing propagation of Epimedium by division, since this is the method currently used by producers. When propagating a slow-growing ornamental plant for which stock supply is limited, using the smallest possible division is necessary to produce significant quantities of liners. Part of this research examined the implications of using small and large divisions for propagation purposes and to yield market quality plants. Since propagators familiar with Epimedium do not agree on the best time to make divisions, a second study was conducted to evaluate when to divide epimediums to optimize success and post-propagation growth.

\section{Materials and Methods}

Plant material. We selected four species that vary in degree of winter foliage retention in USDA Hardiness Zone 5 for this research. E. $\times$ youngianum Fisch. is deciduous, E. $\times$ rubrum Morren is semi-evergreen, $E$. $\times$ ver- sicolor 'Sulphureum' Morren is evergreen to a greater degree than rubrum, and E. pinnatum ssp. colchicum Boiss. is evergreen. Rhizome length also varies among the four experimental species. E. pinnatum ssp. colchicum and $E$. $\times$ versicolor 'Sulphureum' have 10 to 16 $\mathrm{cm}$ (long), creeping rhizomes, E. × rubrum has 3 to $6 \mathrm{~cm}$ (short), creeping rhizomes, and E. $\times$ youngianum has 1 to $2 \mathrm{~cm}$ (very short), upright rhizomes. Divisions were made from 4-L container-grown stock plants. Dormant stock plants were held in a minimally heated greenhouse ( $\operatorname{set}$ point $0^{\circ} \mathrm{C}$ ) and actively growing plants in a $50 \%$ lath-shaded cold frame until needed for experimentation.

Division size study. The influence of division size on epimedium production was evaluated by making small (single bud) and large (three-bud) divisions for each species on 17 to 18 June 2002 and 2003. Size divisions of $E$. pinnatum ssp. colchicum and $E . \times$ versicolor 'Sulphureum' were planted in $688-\mathrm{mL}$ square pots, while $E$. $\times$ rubrum and $E . \times$ youngianum could be accommodated in $307.3-\mathrm{mL}$ square pots because of their shorter rhizome length. Divisions were made by washing the potting medium from the crown, trimming roots to 10 to $12 \mathrm{~cm}$, then cutting through the crown with a knife. Divisions were potted in Metro Mix 510 Growing Medium(Scotts Co., Marysville, Ohio).

To facilitate the establishment of divisions, they were grown in a greenhouse under $60 \%$ shade for 1 week following division, before being moved to outdoor cold frames. Cold frames were equipped with sand and weed barrier floors, concrete walls and 50\% lath shading. Plants were grown in cold frames until the end of the growing season when 10 of the 20 plants per species per division size were randomly chosen for harvest. The remaining half was overwintered in a minimally heated greenhouse (set point $0{ }^{\circ} \mathrm{C}$ ) and harvested the following spring after grow out.

Fall plant harvest and quantification began on 16 Oct. for both years and required 1 week to complete. On 22 Feb. 2003 and 16 Feb. 2004, the overwintered plants were moved into a greenhouse with set points of $21{ }^{\circ} \mathrm{C}$ day and $17{ }^{\circ} \mathrm{C}$ night and a 16-h photoperiod provided by supplemental high-pressure sodium lighting at $50 \mu \mathrm{mol} \cdot \mathrm{m}^{-2} \cdot \mathrm{s}^{-1}$ for forcing. The previous growing season foliage was removed to prevent interference with new leaf and flower emergence. Spring harvest and quantification began on $24 \mathrm{Apr} .2003$ and 15 Apr. 2004 and required 1 week to complete. Plants were irrigated as needed and provided a soluble $20 \mathrm{~N}-8.74 \mathrm{P}-116.6 \mathrm{~K}$ fertilizer (Peters 20-10-20 Fertilizer, Scotts Co., Marysville, Ohio) at $150 \mathrm{ppm} \mathrm{N}$ every $14 \mathrm{~d}$, during their active growth. Plants were hand-weeded.

Division timing study. Uniform divisions were made on 5 to 6 Mar., 24 to 26 June and 28 to 30 Aug. in 2002 and 27 to 28 Mar., 24 to 26 June and 28 to 30 Aug. in 2003 and potted in 1.4-L nursery containers. E. pinnatum ssp. colchicum and E. $\times$ versicolor 'Sulphureum' divisions consisted of three to five buds, while E. $\times$ rubrum and $E . \times$ youngianum divisions consisted of four to seven buds. Division size 
Table 1. The growth response of large and small divisions of four species of Epimedium by the end of the first growing season.

\begin{tabular}{|c|c|c|c|c|c|c|}
\hline \multirow{2}{*}{$\begin{array}{l}\text { Size } \\
\text { treatment }^{z}\end{array}$} & \multirow{2}{*}{$\begin{array}{c}\text { Leaf area } \\
\left(\mathrm{cm}^{2}\right)\end{array}$} & \multirow{2}{*}{$\begin{array}{l}\text { No. of } \\
\text { leaves }\end{array}$} & \multicolumn{2}{|c|}{ Crown wt (g) } & \multicolumn{2}{|c|}{ Leaf wt (g) } \\
\hline & & & Fresh & Dry & Fresh & Dry \\
\hline$\overline{\text { Large }}$ & $297 a^{y}$ & $7.2 \mathrm{a}$ & $33.6 \mathrm{a}$ & $7.8 \mathrm{a}$ & $5.3 \mathrm{a}$ & $2.0 \mathrm{a}$ \\
\hline Small & $127 \mathrm{~b}$ & $3.1 \mathrm{~b}$ & $11.0 \mathrm{~b}$ & $2.5 \mathrm{~b}$ & $2.2 \mathrm{~b}$ & $0.8 \mathrm{~b}$ \\
\hline
\end{tabular}

${ }^{2}$ Large divisions had on average three buds, small divisions consisted of a single bud.

${ }^{y}$ Mean separation within columns by Fisher's LSD test with different letters denoting significance $(P \leq$ $0.05), \mathrm{n}=80$.
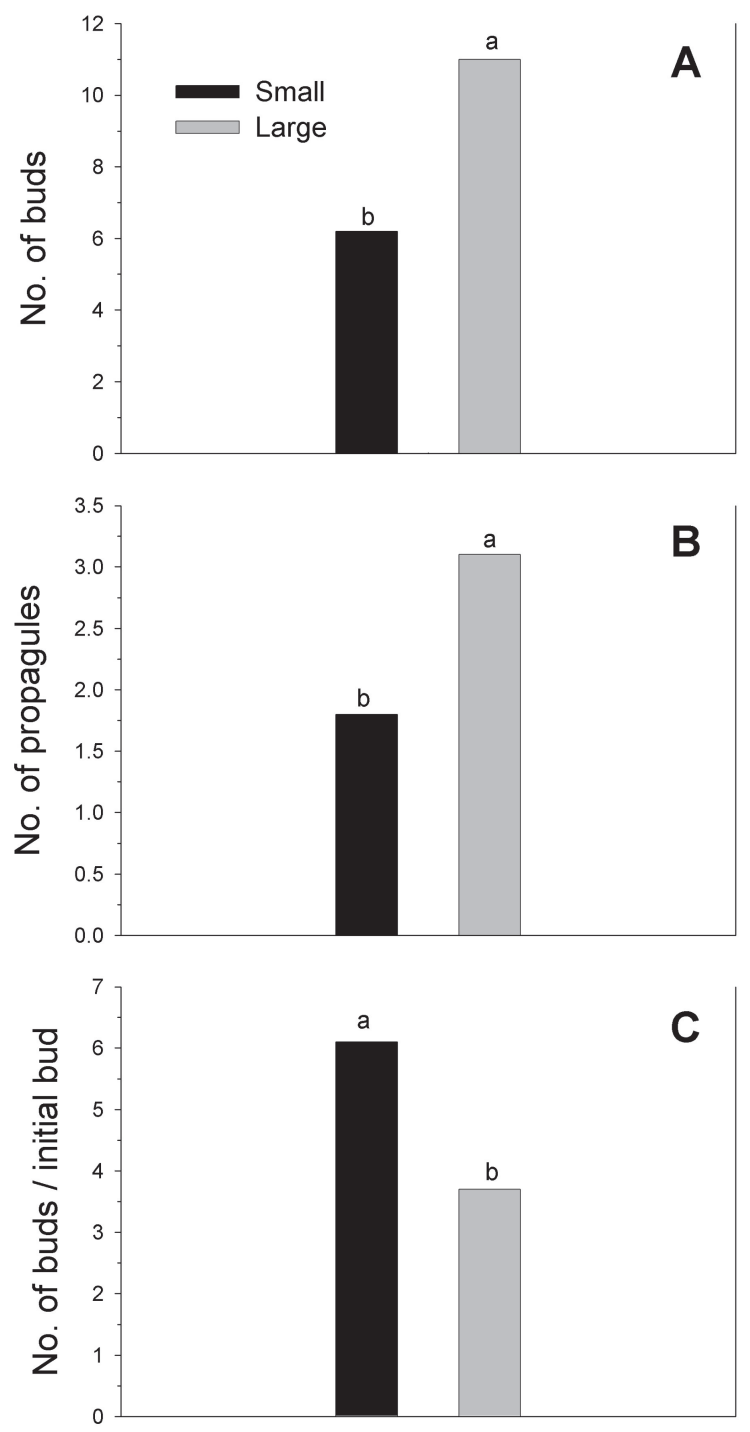

Fig. 1. Effect of large and small divisions of four species of Epimedium on (A) number of buds, (B) number of propagules, and (C) number of buds per initial bud produced by the end of the first growing season.

chosen for each species was based on knowledge of growth potential and habit. Divisions were made as described for the size study and potted in the same growing medium.
March divisions were grown in a greenhouse with set points of $21^{\circ} \mathrm{C}$ day and $17^{\circ} \mathrm{C}$ night and natural lighting for 8 weeks following division, before being moved to cold frames. June and August divisions were instead grown in a greenhouse under $60 \%$ shade for 1 week following division, before being moved to cold frames.

Plants were held in cold frames, similar to those described for the size study, until the end of the growing season when 10 of the 20 plants per species per division timing were randomly chosen for harvest. The remaining half was overwintered in a minimally heated greenhouse (set point $0^{\circ} \mathrm{C}$ ) and harvested the following spring after grow out. Fall plant harvest and quantification began on 22 Oct. of both years and required 1 week to complete. Overwintered plants were brought into the greenhouse for forcing at the same times reported for the size study, and were exposed to similar greenhouse conditions. Spring harvest and quantification began on 30 Apr. 2003 and 21 Apr. 2004 and required 1 week to complete. Plants were irrigated, fertilized and weeded as described for the size study.

Data collection. For both division size and timing studies, plant harvest was accomplished by un-potting the plants, shaking the potting media from the roots and washing the crowns. During plant harvest in the fall, the number of leaves and buds were counted. The number of buds produced per initial bud was calculated by dividing number of buds by the average number of initial buds per treatment. To estimate propagation potential, the number of two to three bud divisions (propagules) that could be made from each plant was determined. Crown fresh weight, which reflects the combined weight of both roots and rhizomes, was recorded. Leaf area was measured using a leaf area meter(LI-3100; LI-COR, Lincoln, Nebr.).

During plant harvest in the spring, the number of leaves, leaf and crown fresh and dry weights, leaf area, and plant height and width were recorded. Plant height was measured from the potting medium surface to the apex of the foliage. Plant width was measured twice, at right angles to each measurement. Plant size was then estimated by multiplying height $x$ width one $\times$ width two. For overwintered and forced plants, the number of flower scapes was counted on 12 to 15 Mar. 2003 and 5 to 8 Mar. 2004.

Experimental design and statistical analysis. Both division size and timing studies were repeated for 2 years. Size study plants were arranged in the cold frames during the outdoor growing season and in the greenhouse following a period of dormancy as a randomized complete block design with four species and two division sizes. For the timing study, species were arranged as a randomized complete block design for each division time during the outdoor growing season. For overwintered plants forced in the greenhouse, the experimental design was a randomized complete block design with four species and three division timings. Fall and spring data was analyzed separately for both studies. The data from both years were combined for statistical analysis resulting in 20 replications per treatment for both studies. Year was included as a random effect in the statistical model. Analysis of variance (ANOVA) was performed on data using statistical analysis systems (SAS Institute, 1999) and the mixed (PROC MIXED) procedure.

\section{Results and Discussion}

Division size study. Large divisions produced bigger plants at the end of the growing season than small divisions. While some interactions were significant, in most cases they were rate of change interactions, following similar trends to the size main effect. Large divisions produced more buds, potential propagules, greater fresh and dry weights, more leaves and leaf area compared to small divisions for all species (Table 1, Fig.1). However, small divisions yielded more buds per initial bud than large divisions for all species (Fig. 1). Twice as many buds developed per initial bud for small divisions of $E$. $\times$ rubrum than for large divisions. Harvey and Brand (2002) found that using small (one to two tiller bud) divisions during propagation of the slow-growing ornamental grass Hakonechloa macra Makino 'Aureola' increased tiller bud production efficiency. In another study, small divisions were found to be more useful than

Table 2. The growth and flowering response of large and small divisions of four species of Epimedium following a period of dormancy.

\begin{tabular}{|c|c|c|c|c|c|c|c|c|}
\hline \multirow{2}{*}{$\begin{array}{l}\text { Size } \\
\text { treatment }^{z}\end{array}$} & \multirow{2}{*}{$\begin{array}{c}\text { Plant size } \\
\left(\mathrm{cm}^{3}\right)\end{array}$} & \multirow{2}{*}{$\begin{array}{c}\text { Leaf area } \\
\left(\mathrm{cm}^{2}\right)\end{array}$} & \multirow{2}{*}{$\begin{array}{l}\text { No. of } \\
\text { leaves }\end{array}$} & \multirow{2}{*}{$\begin{array}{c}\text { No. of flower } \\
\text { scapes }\end{array}$} & \multicolumn{2}{|c|}{ Crown wt (g) } & \multicolumn{2}{|c|}{ Leaf wt (g) } \\
\hline & & & & & Fresh & Dry & Fresh & Dry \\
\hline Large & $10074 \mathrm{a}^{\mathrm{y}}$ & $607 \mathrm{a}$ & $23.1 \mathrm{a}$ & $3.9 \mathrm{a}$ & $42.4 \mathrm{a}$ & $11.1 \mathrm{a}$ & $10.0 \mathrm{a}$ & $3.7 \mathrm{a}$ \\
\hline Small & $9711 \mathrm{a}$ & $434 \mathrm{~b}$ & $14.1 \mathrm{~b}$ & $2.5 \mathrm{~b}$ & $18.4 \mathrm{~b}$ & $4.3 \mathrm{~b}$ & $7.3 \mathrm{~b}$ & $2.6 \mathrm{~b}$ \\
\hline
\end{tabular}

${ }^{2}$ Large divisions had on average three buds, small divisions consisted of a single bud.

${ }^{\mathrm{y}}$ Mean separation within columns by Fisher's LSD test with different letters denoting significance $(P \leq 0.05)$, $\mathrm{n}=80$.

xPlant size is the product of two plant widths taken at right angles to each other and foliage height. 
Table 3. The growth response of March, June and August divisions of four species of Epimedium at the end of the first growing season.

\begin{tabular}{|c|c|c|c|c|c|c|}
\hline \multirow{2}{*}{$\begin{array}{l}\text { Timing } \\
\text { treatment }^{2}\end{array}$} & \multirow{2}{*}{$\begin{array}{c}\text { Leaf area } \\
\left(\mathrm{cm}^{2}\right)\end{array}$} & \multirow{2}{*}{$\begin{array}{l}\text { No. of } \\
\text { leaves }\end{array}$} & \multicolumn{2}{|c|}{ Crown wt $(\mathrm{g})$} & \multicolumn{2}{|c|}{ Leaf wt $(\mathrm{g})$} \\
\hline & & & Fresh & Dry & Fresh & Dry \\
\hline March & $608 \mathrm{a}^{z}$ & $19.0 \mathrm{a}$ & $83.3 \mathrm{a}$ & $21.5 \mathrm{a}$ & $10.3 \mathrm{a}$ & $3.7 \mathrm{a}$ \\
\hline June & $526 \mathrm{~b}$ & $11.4 \mathrm{~b}$ & $52.1 \mathrm{~b}$ & $13.1 \mathrm{~b}$ & $8.7 \mathrm{~b}$ & $3.2 \mathrm{~b}$ \\
\hline August & $402 \mathrm{c}$ & $49.6 \mathrm{~b}$ & $30.7 \mathrm{c}$ & $7.9 \mathrm{c}$ & $6.9 \mathrm{c}$ & $2.7 \mathrm{~b}$ \\
\hline
\end{tabular}

${ }^{\mathrm{z}}$ Mean separation within columns by Fisher's LSD test with different letters denoting significance $(P \leq$ $0.05), \mathrm{n}=80$.
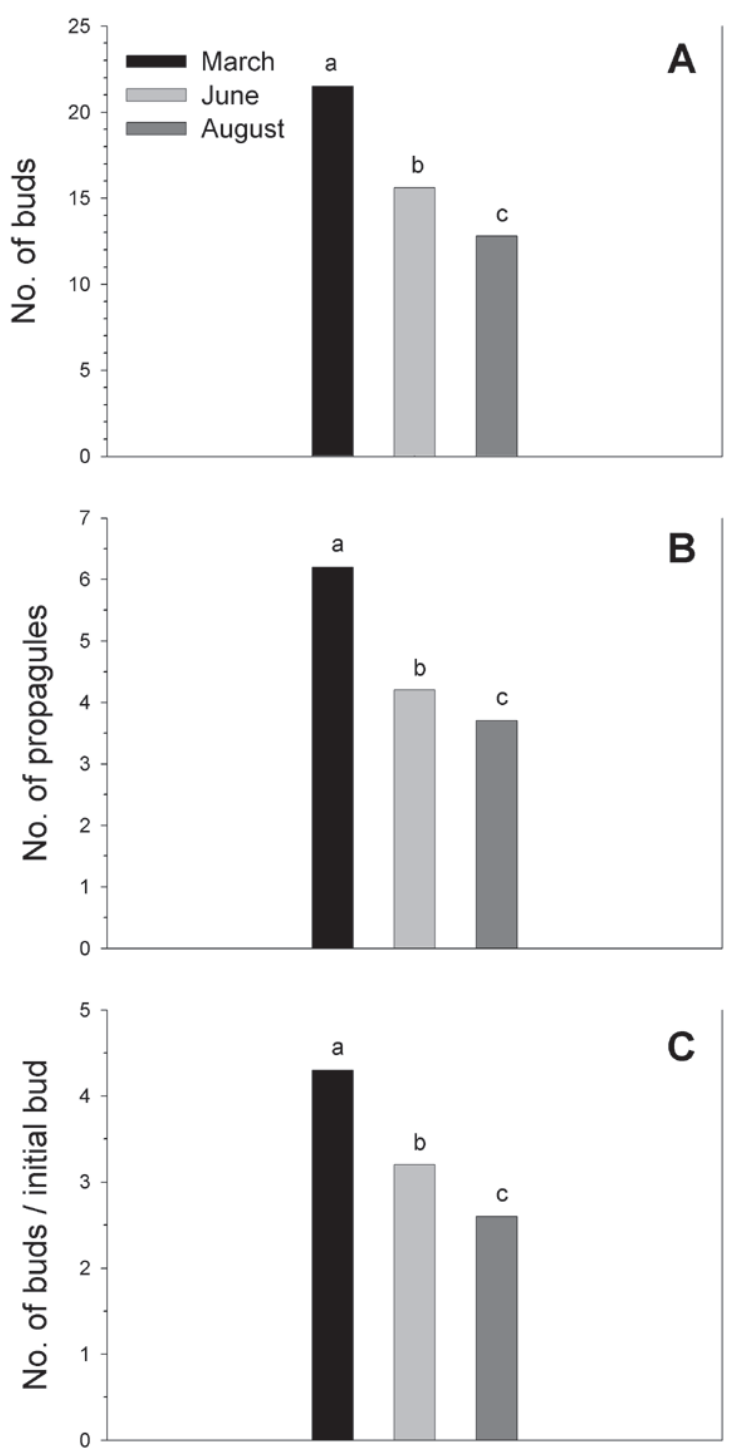

Fig. 2. Effect of March, June and August divisions of four species of Epimedium on (A) number of buds, (B) number of propagules, and (C) number of buds per initial bud produced by the end of the first growing season.

large divisions during propagation of several common ornamental grasses including Cala- magrostis, Miscanthus, Panicum and Pennisetum (Brand, 1999). As seen with Hakonechloa, we found that small (single bud) divisions of epimedium increase bud production efficiency. Following two propagation cycles, a grower using single bud divisions would be able to produce buds, while one using three bud divisions would have produced slightly over 1300 new buds.

When plants were grown in the greenhouse following a dormant period, plants from large divisions produced more vegetative growth than plants from small divisions, with the exception of plant size (Table 2). However, if growth is measured in comparison to initial division size, small divisions grew more than large divisions. Small divisions were initially one-third the size of large divisions (one vs. three buds), but following spring forcing, small divisions were at least $60 \%$ the size of large divisions for most growth parameters (Table 2). Since plants from large divisions had more leaves and greater leaf area than plants from small divisions, but similar plant size or volume, they were more densely foliated and full than small division plants. Large division plants produced $56 \%$ more flower scapes than small division plants.

In summary, the initial size of rhizome divisions should be dictated by the goals of the propagator. If the intention is to rapidly produce marketable plants, larger divisions will yield fuller plants with more inflorescences than small divisions. However, if the goal is to increase the number of growing points with a delayed market schedule, then dividing to small sizes is desired.

Division timing study. At fall harvest, we determined that plant performance generally $>3600$ new buds from 100 initial declined as divisions were made later in the season (Table 3, Fig. 2). While some interactions were significant, in most cases they were rate of change interactions, following similar trends to the timing main effect. March divisions produced $68 \%$ more buds and $65 \%$ more buds per initial bud than August divisions and $22 \%$ and $34 \%$ more than June divisions (Fig. 2 ). In addition, March divisions produced $68 \%$ more propagules than August divisions and $48 \%$ more than June divisions. June divisions performed better than August divisions with the exception of leaf count and leaf dry weight (Table 3).

Following a period of dormancy, March and June divisions produced bigger plants than August divisions (Table 4). March and June divided plants produced more leaves and flower scapes, greater leaf fresh weight, leaf dry weight, plant size and more leaf area than August divided plants. Crown weights progressively decreased from March to June to August. March plants produced $92 \%$ and June plants $74 \%$ more flower scapes than August plants.

Our results indicate that early spring to early summer is an acceptable time for division of Epimedium, however, propagators trying to maximize the multiplication of epimedium growing points should divide rhizomes in March, when dormant. Furthermore, we found there to be no difference in the optimal timing for division of the deciduous, semievergreen and evergreen species examined in this research. In fact, March was the best time for division, August the worst time and June division generally ranked in the middle for all species. Epimedium grower and breeder Darrell Probst (1998, 2001) suggests that deciduous species be divided in either fall or spring, after young leaves have hardened off, while evergreen species perform better if divided from late August through September. One possible reason our conclusions differ from Probst's recommendations is that his suggestions are based on numerous species of Epimedium while this research focused on only four species. Additionally, propagation success at different times can be influenced by production factors such as the availability of skilled labor, the capacity to provide protected conditions for overwintering, and the ability to provide recently divided plants with environmentally controlled conditions.

The importance of division timing to propagation success is not only seen with Epimedium, but also with trillium and bunchberry, two shade tolerant, slow-growing herbaceous perennials (Cullina, 2000; Nau, 1996; Still, 1980; Walters, 1982). Successful propagation of Trillium requires careful removal of naturally occurring crown offshoots in autumn, while

Table 4. The growth and flowering response of March, June and August divisions of four species of Epimedium following a period of dormancy.

\begin{tabular}{|c|c|c|c|c|c|c|c|c|}
\hline \multirow{2}{*}{$\begin{array}{l}\text { Timing } \\
\text { treatment }^{2}\end{array}$} & \multirow{2}{*}{$\begin{array}{l}\text { Plant size } \\
\qquad\left(\mathrm{cm}^{3}\right)\end{array}$} & \multirow{2}{*}{$\begin{array}{c}\text { Leaf area } \\
\left(\mathrm{cm}^{2}\right)\end{array}$} & \multirow{2}{*}{$\begin{array}{l}\text { No. of } \\
\text { leaves }\end{array}$} & \multirow{2}{*}{$\begin{array}{c}\text { No. of flower } \\
\text { scapes }\end{array}$} & \multicolumn{2}{|c|}{ Crown wt (g) } & \multicolumn{2}{|c|}{ Leaf wt $(\mathrm{g})$} \\
\hline & & & & & Fresh & Dry & Fresh & Dry \\
\hline June & 18599 a & $1313 \mathrm{a}$ & $37.5 \mathrm{a}$ & $6.6 \mathrm{a}$ & $78.0 \mathrm{~b}$ & $22.9 \mathrm{~b}$ & $20.3 \mathrm{a}$ & $7.5 \mathrm{a}$ \\
\hline
\end{tabular}

${ }^{2}$ Mean separation within columns by Fisher's LSD test with different letters denoting significance $(P \leq 0.05), \mathrm{n}=80$.

yPlant size is the product of two plant widths taken at right angles to each other and foliage height. 
shoot growth and rhizome spread of Cornus canadensis (Bunchberry) is maximized when divisions are made in April as opposed to June (Cullina, 2000; Haynes et al., 2003).

\section{Literature Cited}

Brand, M.H. 1999. Small divisions of ornamental grasses produce the best growth following direct potting. HortScience 34:1126-1128.

Cullina, W. 2000. Growing and propagating wildflowers. Houghton Mifflin Co., New York.

Harvey, M.P. and M.H. Brand. 2002. Division size and shade density influence growth and container production of Hakonechloa macra Makino
'Aureola'. HortScience 37:196-199.

Haynes, J.G. and J.M. Smagula. 2003. Rooting and establishment of bunchberry stem cuttings as affected by propagation date, K-IBA, rooting duration, and by division or cuttage. HortScience 38:92-96.

Nau, J. 1996. Ball perennial manual: Propagation and production. Ball Publ., Batavia, Ill.

Probst, D. 2004. Garden vision catalog. 2004. Garden Vision, Hubbardston, Mass

Probst, D. 2001. Up-and-coming epimediums. Fine Gardening 80:44-47.

Probst, D. 1998. Garden elegance. Amer. Nurseryman. 187(5):34-40.

SAS Institute. 1999. Software release 8.02. SAS
Inst., Cary, N.C.

Stearn, W.T. 2002. The genus Epimedium and other herbaceous Berberidaceae. Timber Press, Portland, Ore.

Still, S. 1980. Manual ofherbaceous ornamental plants. 4th ed. Stipes Publ. L.L.C., Champaign, Ill.

Sunny Border Incorporated [P. Bennerup (ed.)]. 2003. Sunny Border catalog. Sunny Border Inc., Kensington, Conn.

The Plant Group Incorporated [I. Feinberg (ed.).]. 2003. Plant group catalog. The Plant Group Inc., North Franklin, Conn.

Walters, J. 1982. Propagation of herbaceous perennials. Combined Proc. Intl. Plant Propagator's Soc. 32:583-588 